\title{
Theoretical Calculation and Analysis on the Composite Rock-Bolt Bearing Structure in Burst-Prone Ground
}

\author{
Liang Cheng,, Yidong Zhang, ${ }^{2}$ Ming Ji, ${ }^{1}$ Mantang Cui, ${ }^{1}$ Kai Zhang, ${ }^{1}$ and Minglei Zhang ${ }^{1}$ \\ ${ }^{1}$ School of Mines, Key Laboratory of Deep Coal Resource Mining, Ministry of Education of China, \\ China University of Mining \& Technology, Xuzhou 221116, China \\ ${ }^{2}$ State Key Laboratory of Coal Resources and Safe Mining, School of Mines, China University of Mining \& Technology, \\ Xuzhou 221116, China \\ Correspondence should be addressed to Ming Ji; jiming@cumt.edu.cn
}

Received 18 March 2015; Accepted 12 May 2015

Academic Editor: Giovanni Garcea

Copyright (C) 2015 Liang Cheng et al. This is an open access article distributed under the Creative Commons Attribution License, which permits unrestricted use, distribution, and reproduction in any medium, provided the original work is properly cited.

Given the increase in mining depth and intensity, tunnel failure as a result of rock burst has become an important issue in the field of mining engineering in China. Based on the Composite Rock-Bolt Bearing Structure, which is formed due to the interaction of the bolts driven into the surrounding rock, this paper analyzes a rock burst prevention mechanism, establishes a mechanical model in burst-prone ground, deduces the strength calculation formula of the Composite Rock-Bolt Bearing Structure in burst-prone ground, and confirms the rock burst prevention criterion of the Composite Rock-Bolt Bearing Structure. According to the rock burst prevention criterion, the amount of the influence on rock burst prevention ability from the surrounding rock parameters and bolt support parameters is discussed.

\section{Introduction}

In China, coal reserves have proven to amount to as much as 5059.2 billion tons, constituting nearly $11.1 \%$ of the total reserves worldwide [1]. Coal reserves at the depth of less than $1000 \mathrm{~m}$ have been found to be 2950 billion tons, which is $53 \%$ of the total reserves in the world, and at a depth less than $600 \mathrm{~m}$ are $78 \%$ of the total worldwide reserves [2]. According to related statistics, with the decrease of coal reserves, the increase of coal mining depth is with an average speed of $8 \sim 12$ meters per year [3]. In eastern coal mines the typical average speed is $20 \sim 25$ meters per year. It is predicted that, in 20 years, the depth of most coal mines will reach 1000 1500 $\mathrm{m}$ in China $[4,5]$. The frequency and intensity of rock bursts will increase with the increase of coal mining depth [6]. Therefore, the issue of burst-prone ground control has become a significant problem in the field of mining engineering in China. As far as tunnel rock bursts are concerned, many research studies have been conducted and have come to some meaningful conclusions [7-11]. Some researchers made some measures to prevent rock bursts in the tunnel. Gao et al. [12] established a strong-soft-strong mechanical model for controlling the burst-prone ground, such as decreasing the shock center stress, applying softstructure, and enhancing support strength that can prevent rock bursts. Based on the study of Gao et al., Zhang [13] established a strong-weak-strong-weak mechanics model for controlling the deep burst-prone ground. Lü and Pan [14] applied a rigid-flexible coupling support method, which was setting good buffering and absorption materials between rigid support and the surrounding rocks, to decrease shock stress and maintain tunnel stability. Besides simply improving the support structure of the surrounding rock, the bolt support was a measure to prevent rock bursts in the tunnel. Gao et al. [15] indicated that if the tunnel support system can absorb the whole or part of the shock energy when rock bursts occurred, the shock disaster degree can be decreased. They also put forward 3D anchor-cables with round steel 
bolts, $\Pi$ steel beams, and metal nets to prevent rock bursts in the tunnel. Li et al. [16] took some important steps such as designing a more reasonable width for the narrow coal pillar, setting a weak interlayer, and applying high performance bolts to prevent rock bursts and rock stability problems in the condition of gob-side entry. The above studies did not make a detailed analysis of the bearing capacity of the surrounding rock and the impact on rock burst prevention by bolt support was not fully considered. Cai [17] presented seven principles which can lead to making the right judgment and decision with regard to rock support design in burst-prone ground.

Based on the Composite Rock-Bolt Bearing Structure, which is formed due to the interaction of the bolt and surrounding rock [18-21], Gao's scientific paper dealt with an analysis of the rock burst prevention mechanism, established a mechanical model for burst-prone ground control, deduced the strength calculation formula of the Composite Rock-Bolt Bearing Structure, and determined the rock burst prevention criterion of Composite Rock-Bolt Bearing Structure. According to the rock burst prevention criterion, the affections of surrounding rock and bolt parameters on the rock burst prevention ability were discussed.

\section{Rock Burst Prevention Mechanism}

The shock stress caused by the coal mining activities is a critical factor of tunnel failure in the burst-prone ground. The shock stress propagated from the shock center and the initial rock stress has a superposition. Once the stacked stress is more than the ultimate strength of the surrounding rock, the equilibrium state of the surrounding rock would be lost. As a result, the rock fails instantaneously due to the repeated tensile and compression by the stress wave [12].

To maintain the tunnel stability, the tunnel's roof and sides are supported by bolts with some pretightening force. After the installation of multiple bolts with reasonable bolt length and density, the Composite Rock-Bolt Bearing Structure with some strength and deformability is formed due to the interaction of the bolts and the surrounding rock [21]. The bearing characteristic of the Composite Rock-Bolt Bearing Structure is influenced by the tunnel and the bolt support parameters. The bearing structure can bear the shock stress and prevent rock burst when the parameters are appropriate.

\section{Mechanical Model}

Given the activities involved typically with mining, the force of the shock center induces a stress wave, which propagates to the tunnel. Firstly, the stress wave propagates in the intact rock mass and then passes to the Composite Rock-Bolt Bearing Structure. Once the shock stress is more than the strength of the Composite Rock-Bolt Bearing Structure, rock burst would occur in the tunnels. The mechanical model for burst-prone ground control is given in Figure 1.

3.1. Basic Hypothesis. (1) Homogeneous broken rock circles around the tunnel are formed after the tunnel excavation and the Composite Rock-Bolt Bearing Structure is in the broken area [22].
(2) The rock material follows the Mohr-Coulomb yield criterion under shock stress as shown in the following formula [23]:

$$
\begin{aligned}
c_{d} & =\sigma_{c d} \frac{1-\sin \varphi}{2 \cos \varphi}, \\
\sigma_{1 d} & =\sigma_{c d}+\sigma_{3} \frac{1+\sin \varphi}{1-\sin \varphi},
\end{aligned}
$$

where $\varphi$ is the internal friction angle, $c_{d}$ is dynamic cohesion of the Composite Rock-Bolt Bearing Structure, $\sigma_{3}$ is the minor principal stress, $\sigma_{1 d}$ is the dynamic triaxial compressive strength, and $\sigma_{c d}$ is the dynamic uniaxial compressive strength. Dynamic cohesion and strength mean the cohesion and strength under dynamic loading and are larger than them under static loading commonly.

(3) The bolt support is intensive and the working resistance distributes on the tunnel surface evenly. The overlying stress distributes on the external surface of the Composite Rock-Bolt Bearing Structure evenly.

(4) The tunnel cross section forms a circle and the surrounding rock is an isotropic homogeneous plane strain model without any creeping and viscosity behavior.

(5) The stress wave can be regarded as having normal incidences and is well-distributed when it propagates to the Composite Rock-Bolt Bearing Structure.

3.2. Strength Calculation of the Composite Rock-Bolt Bearing Structure. A mechanical analysis was based on half of the Composite Rock-Bolt Bearing Structure as shown in Figure 1(b). It is assumed that $N$ bolts are applied in each semicircular tunnel section. Bolt intervals can be described as

$$
D_{a}=\frac{\pi r_{0}}{N-1}
$$

where $D_{a}$ is bolt interval and $r_{0}$ is tunnel radius.

The conical compression zone around the bolt head can be approximately described as [24]

$$
b=\frac{\left(r_{0}+L\right)}{r_{0}} \frac{D_{a}}{2},
$$

where $L$ is the length of bolt.

The thickness of the Composite Rock-Bolt Bearing Structure is equal to the bolt length minus the thickness of the conical compression zone:

$$
B=L-b=L-\frac{\pi\left(r_{0}+L\right)}{2(N-1)} .
$$

The Composite Rock-Bolt Bearing Structure is under the action of the vertical force, the homogeneous stress, and the support strength. In the horizontal direction, external force of the Composite Rock-Bolt Bearing Structure can achieve selfbalancing. Therefore, to achieve an external balancing force, a vertical balancing force is needed. 


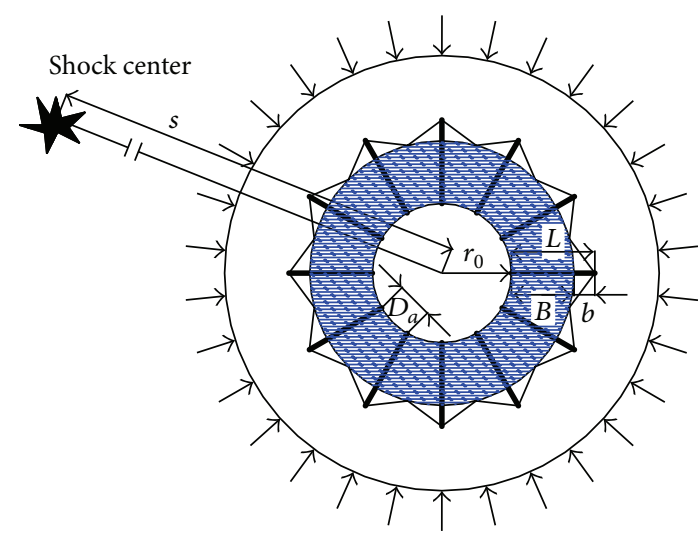

(a) Mechanical model of surrounding rock stability

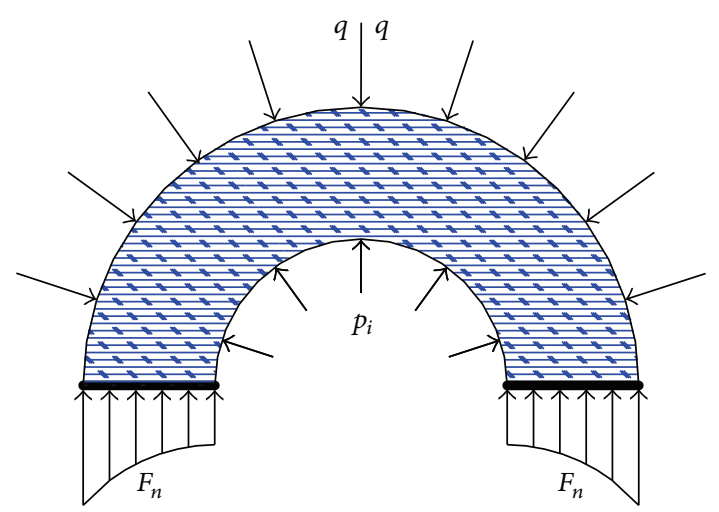

(b) Mechanical model of Composite Bolt-Rock Bearing Structure

FIGURE 1: Mechanical model for burst-prone ground control.

3.2.1. Vertical Force Calculation of Composite Rock-Bolt Bearing Structure. Bolt support strength can be described as

$$
p_{i}=\frac{Q_{s}}{D_{a} D_{b}}
$$

where $Q_{s}$ is bolt working resistance and $D_{b}$ is bolt space between rows.

In order to fully use the bolt's working resistance, the bolt should be yielding but not to the extent of causing tensile failure. Therefore, the bolt's working resistance can be described as

$$
Q_{s}=\frac{\pi d^{2} \sigma_{s}}{4}
$$

where $d$ is bolt diameter and $\sigma_{s}$ is bolt yield strength.

It is assumed that surrounding rock is in a limit state under external stress. Based on the Mohr-Coulomb yield criterion, the tunnel surface stress can be described as

$$
p_{c}=p_{i} \frac{1+\sin \varphi}{1-\sin \varphi}+\frac{2 c_{d} \cos \varphi}{1-\sin \varphi}
$$

where $p_{c}$ is the tangential stress of the semicircular tunnel surface, $\varphi$ is the internal friction angle of the Composite Rock-Bolt Bearing Structure, and $c_{d}$ is the dynamic cohesion of the Composite Rock-Bolt Bearing Structure.

The vertical force of the Composite Rock-Bolt Bearing Structure can be described as

$$
F_{n}=\int_{0}^{B}\left\{\left[p_{i}+f(x)\right] \frac{1+\sin \varphi}{1-\sin \varphi}+\frac{2 c_{d} \cos \varphi}{1-\sin \varphi}\right\} d x
$$

where $f(x)$ is the distribution function of the radial stress along radius direction.
3.2.2. Vertical Force Calculation of Bolt Support Strength. A mechanism analysis is developed on an arc block of the tunnel surface:

$$
\begin{aligned}
& d u=r_{0} d \alpha, \\
& F_{p}=\int_{s^{\prime}} p_{i} \sin \alpha d^{\prime} s=\int_{0}^{\pi} p_{i} R_{0} \sin \alpha d \alpha .
\end{aligned}
$$

3.2.3. Vertical Force Calculation of Composite Rock-Bolt Bearing Structure's Overlying Homogeneous Stress. Similarly, a mechanism analysis is developed on an arc block of the Composite Rock-Bolt Bearing Structure which is shown in Figure 2. Consider

$$
\begin{aligned}
& d u=\left(r_{0}+B\right) d \alpha, \\
& F_{q}=\int_{u} q \sin \alpha d u=\int_{0}^{\pi} q\left(r_{0}+B\right) \sin \alpha d \alpha .
\end{aligned}
$$

3.2.4. Static Equilibrium Equation. In the vertical direction, the static equilibrium equation can be described as

$$
2 F_{n}=F_{q}-F_{p} .
$$

After submitting formulas (8), (9), and (10) into formula (11), the result is

$$
\begin{aligned}
& 2 \int_{0}^{B}\left\{\left(p_{i}+k r\right) \frac{1+\sin \varphi}{1-\sin \varphi}+\frac{2 c_{d} \cos \varphi}{1-\sin \varphi}\right\} d x \\
& \quad=\int_{0}^{\pi} q\left(r_{0}+B\right) \sin \alpha d \alpha-\int_{0}^{\pi} p_{i} r_{0} \sin \alpha d \alpha,
\end{aligned}
$$

where $f(x)$ is a linear function and its slope rate is $k$.

Therefore, the overlying stress on the Composite RockBolt Bearing Structure can be described as

$$
q=\frac{B\left[\left(p_{i}+k B / 2\right)((1+\sin \varphi) /(1-\sin \varphi))+\left(2 c_{d} \cos \varphi /(1-\sin \varphi)\right)\right]+r_{0} p_{i}}{r_{0}+B}
$$




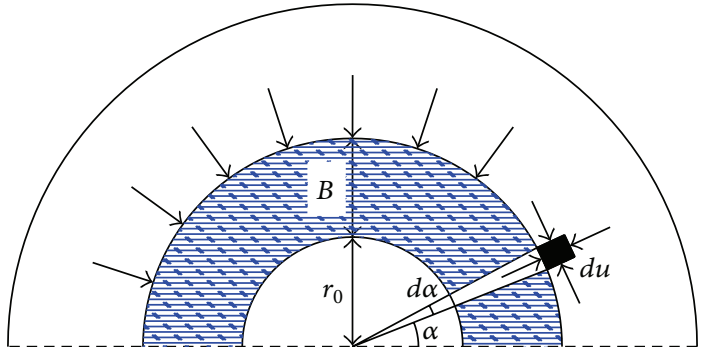

FIGURE 2: Overlying homogeneous stress distribution of Composite Rock-Bolt Bearing Structure.

After submitting formulas (4), (5), and (6) into the overall formula (13), the strength of the Composite Rock-Bolt Bearing Structure can be described as

$$
\begin{aligned}
q= & \frac{L-\pi\left(r_{0}+L\right) / 2(N-1)}{r_{0}+L-\pi\left(r_{0}+L\right) / 2(N-1)}\left\{\left[\frac{\pi d^{2} \sigma_{s}}{4\left(\pi r_{0} /(N-1)\right)^{2}}\right.\right. \\
& \left.+\frac{1}{2} k\left(L-\frac{\pi\left(r_{0}+L\right)}{2(N-1)}\right)\right] \frac{1+\sin \varphi}{1-\sin \varphi}+\frac{2 c_{d} \cos \varphi}{1-\sin \varphi} \\
& \left.+\frac{\pi d^{2} \sigma_{s}}{4\left(\pi r_{0} /(N-1)\right)^{2}} \cdot \frac{r_{0}}{L-\pi\left(r_{0}+L\right) / 2(N-1)}\right\} .
\end{aligned}
$$

3.3. Strength of Stress Wave and Rock Burst Prevention Criterion of Composite Rock-Bolt Bearing Structure. Based on above analysis, the stress of the Composite Rock-Bolt Bearing Structure can be described as

$$
\sigma_{r}=p_{i}+k r .
$$

It is assumed that the energy-dampening index of the stress wave propagation in the medium is $\eta$; hence the peak stress relative to the propagation distance in the medium can be described as [25]

$$
\sigma_{1}=\sigma\left(\frac{s_{0}}{x_{0}}\right)^{-\eta}
$$

where $\sigma$ is the initial shock stress, $s_{0} / x_{0}$ is the relative distance of the stress wave propagation, $x_{0}$ is the unit distance $(1 \mathrm{~m})$, and $s_{0}$ is the distance from shock center to the external surface of the Composite Rock-bolt Bearing Structure.

The incident strength of the stress wave of the external surface of the Composite Rock-Bolt Bearing Structure can be described as

$$
\sigma_{1}=\sigma\left(s-r_{0}-B\right)^{-\eta}
$$

where $s$ is the distance from shock center to tunnel center.

Therefore, the external surface stress of the Composite Rock-Bolt Bearing Structure is described as

$$
\sigma_{B}=\left.\sigma_{r}\right|_{r=B} \sigma_{1} .
$$

When $\sigma_{B} / q<1$, tunnel would not fail under rock burst and let parameter $K$ be

$$
K=\frac{p_{i}+k B+\sigma\left(s-r_{0}-B\right)^{-\eta}}{q} .
$$

Hence, the rock burst prevention criterion of the Composite Rock-Bolt Bearing Structure can be described as $K<$ 1.

It may be indicated by this study and demonstrated by formula (19) that on the one hand the rock burst prevention of the Composite Rock-Bolt Bearing Structure depends on the initial stress, the distance from the shock center to external surface of the Composite Rock-Bolt Bearing Structure, and the energy-dampening index of the stress wave propagation. On the other hand the geometry parameters and the strength of the Composite Rock-Bolt Bearing Structure are important factors that prevent rock burst.

$K$ value is a factor, which performs the stability of burstprone ground. When $K<1$, the Composite Rock-Bolt Bearing Structure can prevent rock burst and the tunnel would not fail. Moreover, the lower the $K$ value, the more stable the tunnel.

\section{Relationships among $K$ Value, Surrounding Rock Parameters, and Bolt Support Parameters}

After the shock center parameters are concerned then the rock burst prevention ability of the Composite Rock-Bolt Bearing Structure depends on the surrounding rock parameters (cohesion and internal friction angle) and the bolt support parameters (bolt length, interval, space, and diameters). The authors of this paper chose only one parameter to investigate the relationships among the $K$ values, the surrounding rock parameters, and the bolt support parameters. The applied parameters are described in Table 1.

After submitting formulas (4), (5), and (14) into formula (19), $K$ value can be described as

$$
\begin{aligned}
K & =\left(\frac{\pi d^{2} \sigma_{s}}{4\left(\pi r_{0} /(N-1)\right)^{2}}+k\left(L-\frac{\pi\left(r_{0}+L\right)}{2(N-1)}\right)+\sigma\left(s-r_{0}-L\right.\right. \\
& \left.\left.+\frac{\pi\left(r_{0}+L\right)}{2(N-1)}\right)^{-\eta}\right) \\
& \cdot\left(\frac { L - \pi ( r _ { 0 } + L ) / 2 ( N - 1 ) } { r _ { 0 } + L - \pi ( r _ { 0 } + L ) / 2 ( N - 1 ) } \left\{\left[\frac{\pi d^{2} \sigma_{s}}{4\left(\pi r_{0} /(N-1)\right)^{2}}\right.\right.\right. \\
& \left.+\frac{1}{2} k\left(L-\frac{\pi\left(r_{0}+L\right)}{2(N-1)}\right)\right] \frac{1+\sin \varphi}{1-\sin \varphi}+\frac{2 c_{d} \cos \varphi}{1-\sin \varphi} \\
& \left.\left.+\frac{\pi d^{2} \sigma_{s}}{4\left(\pi r_{0} /(N-1)\right)^{2}} \cdot \frac{r_{0}}{L-\pi\left(r_{0}+L\right) / 2(N-1)}\right\}\right)^{-1} .
\end{aligned}
$$

It is clear from formula (20) that

(1) there is a negative linear correlation between the $K$ value and the rock cohesion. The $K$ value is the increasing function of the internal friction angle. With the increase of the internal friction angle and cohesion, the likelihood of a rock burst in a tunnel should be decreased. It is consistent with the rock burst prevention mechanism by grouting into broken rock mass to strengthen surrounding rock in field practice; 
TABLE 1: Calculation parameters.

\begin{tabular}{lc}
\hline$r_{0} / \mathrm{m}$ & 2.0 \\
$L / \mathrm{m}$ & 2.4 \\
$N$ & 9 \\
$d / \mathrm{mm}$ & 20 \\
$\sigma_{s} / \mathrm{MPa}$ & 400 \\
$K$ & 0.5 \\
$\varphi$ & 30 \\
$c_{d} / \mathrm{MPa}$ & 1 \\
$\sigma / \mathrm{MPa}$ & 1 \\
$s / \mathrm{m}$ & 500 \\
$\eta$ & 100 \\
\hline
\end{tabular}

(2) there is a negative linear correlation between the $K$ value and the bolt yield strength. It means that the material quality of the bolt influenced the possibility of rock burst in the tunnel;

(3) there is a negative linear correlation between the $K$ value and the bolt diameter. The higher the bolt diameter, the lower the possibility of a rock burst in the tunnel;

(4) when the tunnel radius is increased from $1.4 \mathrm{~m}$ to $2.6 \mathrm{~m}$, the relationship between the $K$ value and the tunnel radius is shown in Figure 3. The higher the tunnel radius, the lower the rock burst prevention ability of the Composite Rock-Bolt Bearing Structure. This indicates that rock burst tends to occur more readily in a larger section tunnel;

(5) when the tunnel section bolt numbers are increased from 5 to 12 and the bolt interval is equal to the bolt space that increased from $0.57 \mathrm{~m}$ to $1.26 \mathrm{~m}$, the relationship between the $K$ value and the bolt interval (space) is shown in Figure 4. As the tunnel support density goes up, the rock burst prevention ability of the Composite Rock-Bolt Bearing Structure may decrease;

(6) when bolt length is increased from $1.6 \mathrm{~m}$ to $2.8 \mathrm{~m}$, the relationship between the $K$ value and the bolt length is shown in Figure 5. As the bolt length goes up, the rock burst prevention ability of the Composite RockBolt Bearing Structure would decrease.

\section{Conclusions}

(1) The Composite Rock-Bolt Bearing Structure with some strength and deformability is formed due to the interaction of the bolt and the surrounding rock and has certain abilities to prevent rock burst in the tunnel.

(2) Based on a circular tunnel, the mechanical model for burst-prone ground control is established and the strength and the rock burst prevention criterion of the Composite Rock-Bolt Bearing Structure are obtained.

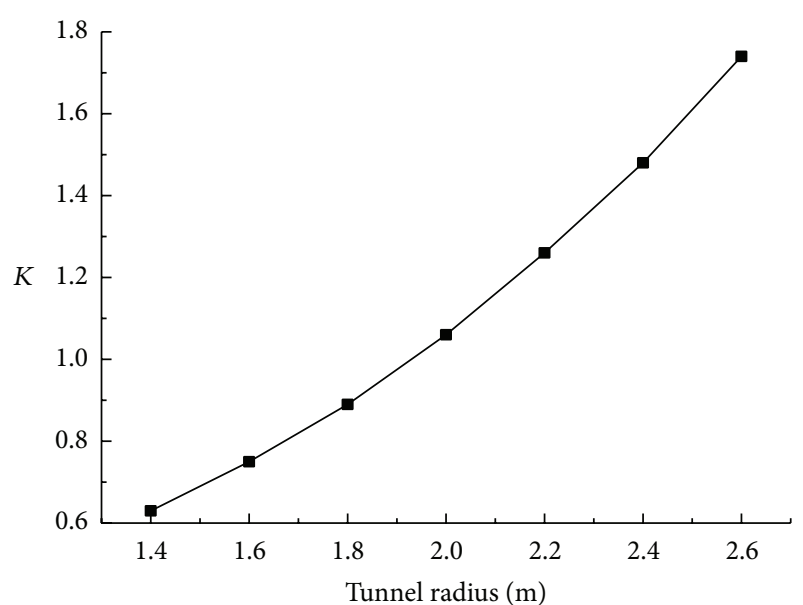

Figure 3: Relationship between $K$ value and tunnel radius.

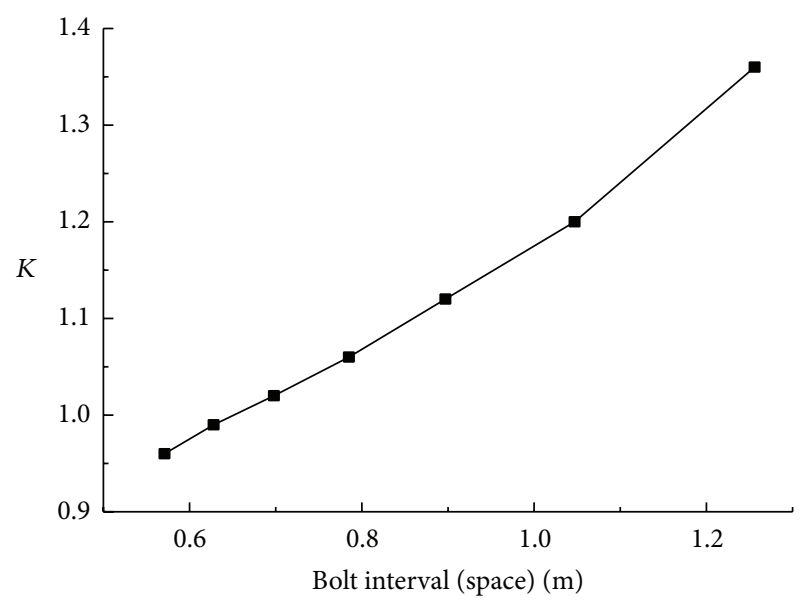

FIGURE 4: Relationship between $K$ value and bolt interval (space).

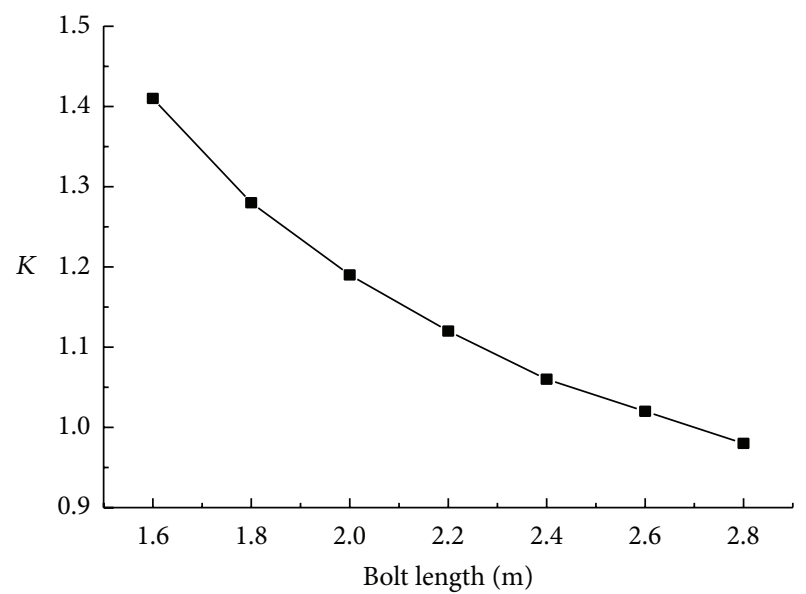

FIGURE 5: Relationship between $K$ value and bolt length.

(3) Based on the rock burst prevention criterion of the Composite Rock-Bolt Bearing Structure, the influence degree on the rock burst prevention ability from the surrounding rock parameters and the bolt 
support parameters is discussed. Rock burst occurs more easily in a large section tunnel; however, the increasing bolt support density, length, and diameter can enhance the rock burst prevention ability of Composite Rock-Bolt Bearing Structure.

\section{Conflict of Interests}

The authors declare that there is no conflict of interests regarding the publication of this paper.

\section{Acknowledgments}

This paper is supported by "Natural Science Foundation of Jiangsu Province, China" (Grant no. BK20130189), and "Priority Academic Program Development of Jiangsu Higher Education Institutions," funded by "Open Projects of State Key Laboratory of Coal Resources and Safe Mining, CUMT (SKLCRSM12X05).”

\section{References}

[1] M. M. Rui, Z. X. Xu, and Z. Y. Su, Geotechnical Anchoring Technology Handbook, China Communications Press, Beijing, China, 2004.

[2] Q. S. Liu, H. Zhang, and T. Lin, "Study on stability of deep rock roadways in coal mines and their support measures," Chinese Journal of Rock Mechanics and Engineering, vol. 23, no. 21, pp. 3732-3737, 2004.

[3] D. Z. Li, Deep Mine Mining Technology, China University of Mining and Technology Press, Xuzhou, China, 2005.

[4] J. P. Du and J. C. Su, Strata Behaviors and Control of Deep Coal Mine Mining, China University of Mining and Technology Press, Xuzhou, China, 2000.

[5] H. P. Xie and S. P. Peng, Basic Theory and Engineering Practice of Deep Mining, Science Press, Beijing, China, 2006.

[6] A. M. Linkov, "Rock bursts and the instability of rock masses," International Journal of Rock Mechanics and Mining Sciences \& Geomechanics Abstracts, vol. 33, no. 7, pp. 727-732, 1996.

[7] Q. X. Huang and Z. N. Gao, "Mechanical model of fracture and damage of coal bump in the entry," Journal of China Coal Society, vol. 26, no. 2, pp. 156-159, 2001.

[8] X. C. Zhang, X. X. Miao, and M. H. Zhai, "Analysis on rock burst mechanism in Sanhejian coal mine," Chinese Journal of Rock Mechanics and Engineering, vol. 17, no. 5, pp. 508-513, 1998.

[9] L. M. Dou and X. Q. He, "Elast-plast-brittle model of the coal-rock-concrete impacting destroy," in Proceedings of the 7th National Rock Mechanics Conference Thesis, Beijing, China, 2002.

[10] G.-Z. Yin, G.-F. Dai, W.-L. Pi, and D.-W. Li, "Study on rock burst using stick slip model," Rock and Soil Mechanics, vol. 26, no. 3, pp. 359-364, 2005.

[11] Y. F. Zhao, Y. S. Pan, and H. J. Yu, "Analysis on circular chamber mine earthquake based on damage model," Rock and Soil Mechanics, no. S2, pp. 347-350, 2004.

[12] M.-S. Gao, L.-M. Dou, N. Zhang, K. Wang, and B.-S. Zheng, "Strong-soft-strong mechanical model for controlling roadway surrounding rock subjected to rock burst and its application," Rock and Soil Mechanics, vol. 29, no. 2, pp. 359-364, 2008.
[13] Y. Zhang, Mechanism and Prevention Technology of Rock Burst for Super Thick Seam Roadway in Deep Ground, China University of Mining \& Technology, Xuzhou, China, 2010.

[14] X. F. Lü and Y. S. Pan, "Stress wave propagation and decay law and test analysis of surrounding rock by rigid-flexible coupling support," Engineering Mechanics, vol. 30, no. 1, pp. 345-349, 2013.

[15] M.-S. Gao, N. Zhang, L.-M. Dou, K. Wang, and J.-G. Kan, "Study of roadway support parameters subjected to rock burst based on energy balance theory," Journal of China University of Mining \& Technology, vol. 36, no. 4, pp. 426-430, 2007.

[16] X.-H. Li, S. Liang, Q.-L. Yao, and Q.-D. Qu, "Control principle and its application of rock burst in roadway driving along goaf with outburst-proneness surrounding rocks," Journal of Mining \& Safety Engineering, vol. 29, no. 6, pp. 751-756, 2012.

[17] M. Cai, "Principles of rock support in burst-prone ground," Tunnelling and Underground Space Technology, vol. 36, no. 6, pp. 46-56, 2013.

[18] Y. D. Zhang and J. P. Li, "Inquiring into the carrying capacity of supporting structure inside coal roof of roadway supported by bolt," Journal of China Coal Society, vol. 24, no. 6, pp. 605-608, 1999.

[19] W. Yu, Q. Gao, and C. Zhu, "Study of strength theory and application of overlap arch bearing body for deep soft surrounding rock," Chinese Journal of Rock Mechanics and Engineering, vol. 29, no. 10, pp. 2134-2142, 2010.

[20] S. Q. Li, Study on Principal of Inner-Outer Bearing Structures Coupling Stabilization for Strata Control around Deep Coal Drifts, Central South University, Changsha, China, 2008.

[21] Y. D. Zhang, Study on bearing characteristic of composite boltrock bearing structure and its application in roadway bolting design [Ph.D. thesis], China University of Mining \& Technology, Xuzhou, China, 2013.

[22] C. J. Hou, Ground Control of Roadways, China University of Mining and Technology Press, Xuzhou, China, 2013.

[23] J. Zhao and H. B. Li, "Estimating the dynamic strength of rock using Mohr-Coulomb and Hoek-Brown criteria," Chinese Journal of Rock Mechanics and Engineering, vol. 22, no. 2, pp. 171-176, 2003.

[24] H. W. Song and B. S. Mu, "Research on load capability and rational thickness of a reinforced broken rock arch," Journal of China University of Mining \& Technology, vol. 26, no. 2, pp. 3335, 1997.

[25] J. Shang, L. Shen, and J. Zhao, "Attenuation law of stress wave in the Bukit Timah granite," Chinese Journal of Rock Mechanics and Engineering, vol. 20, no. 2, pp. 212-215, 2001. 


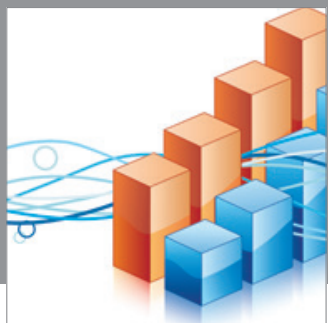

Advances in

Operations Research

mansans

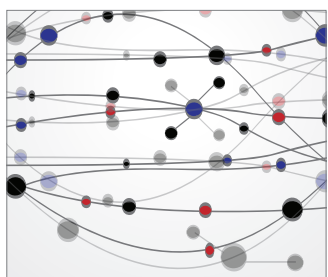

The Scientific World Journal
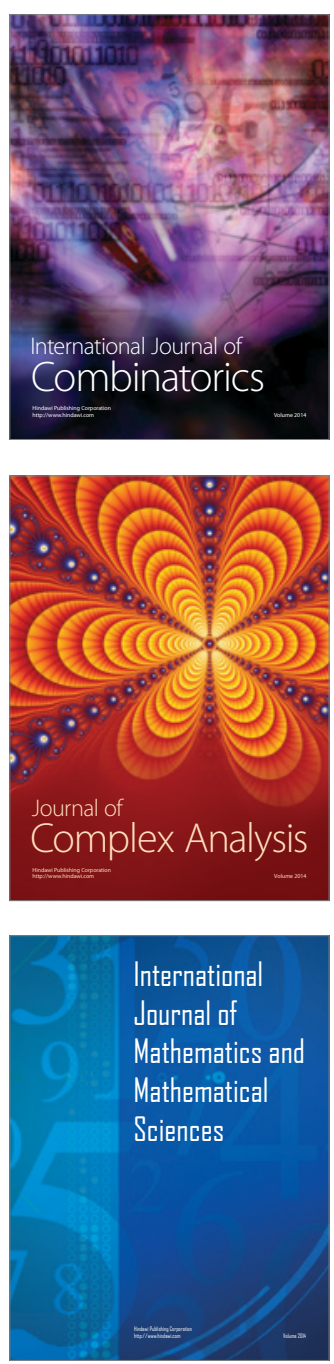
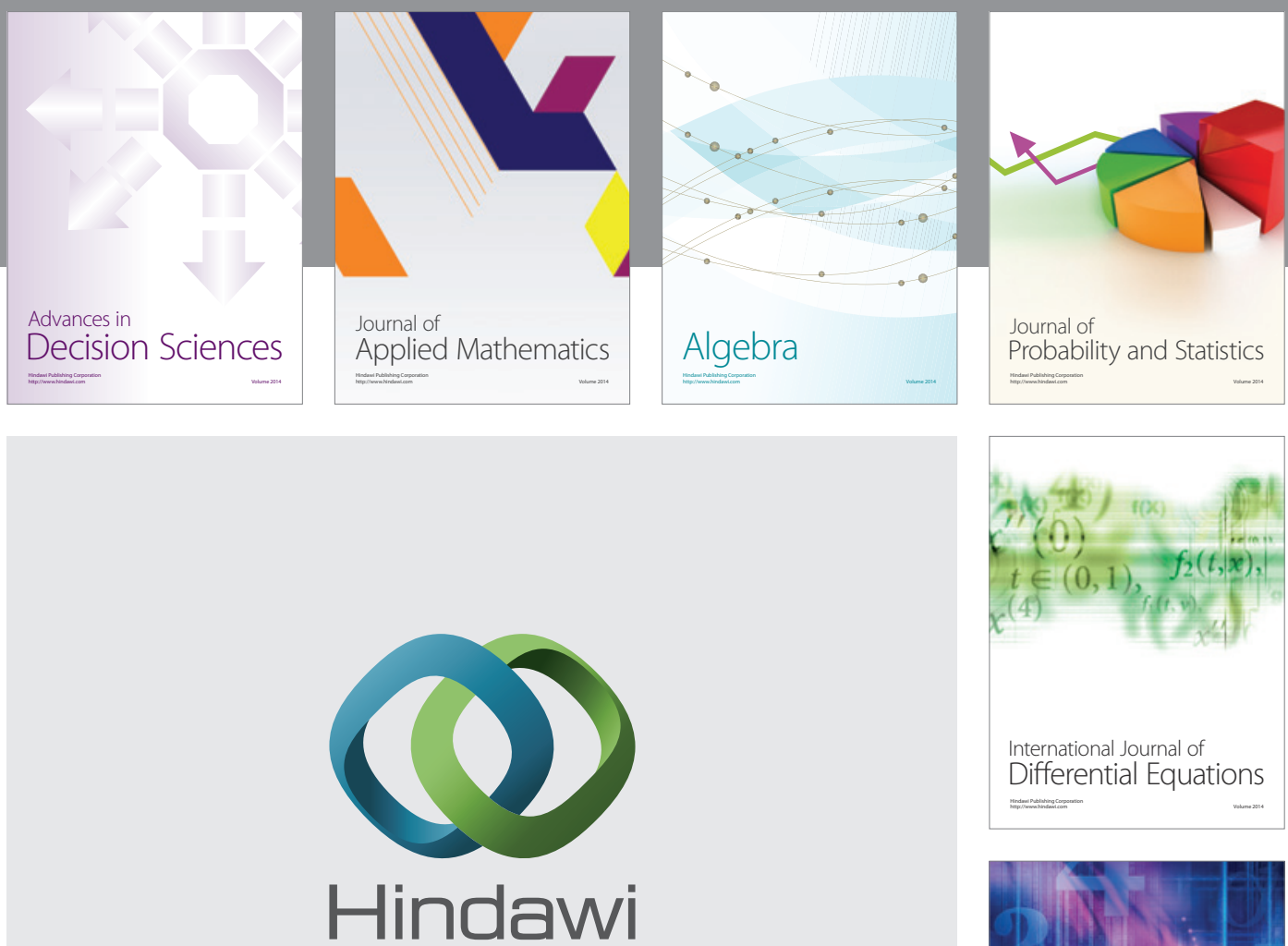

Submit your manuscripts at http://www.hindawi.com
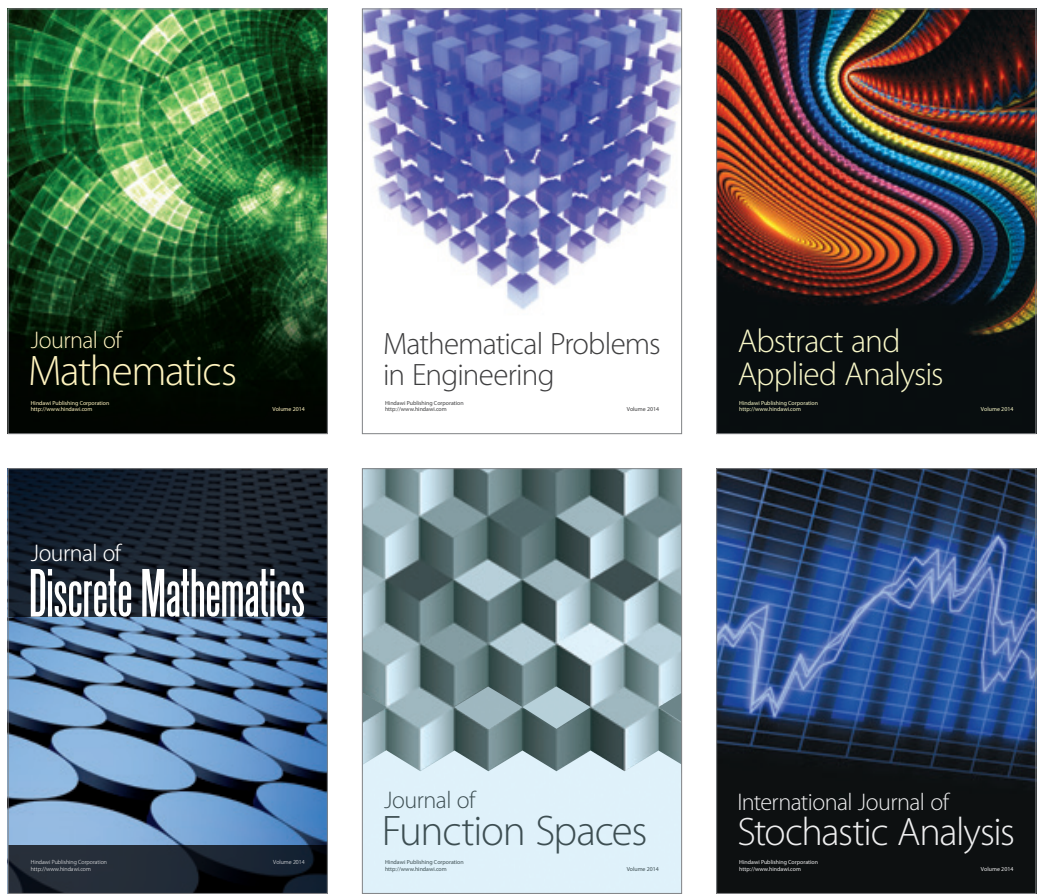

Journal of

Function Spaces

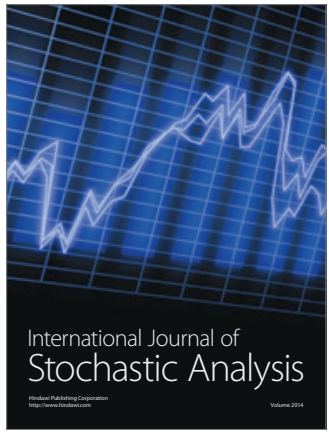

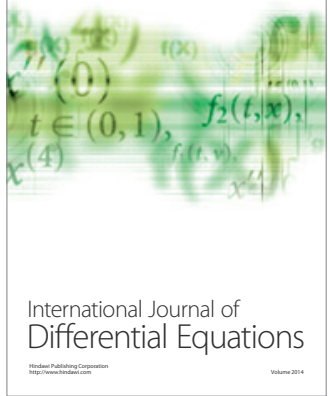
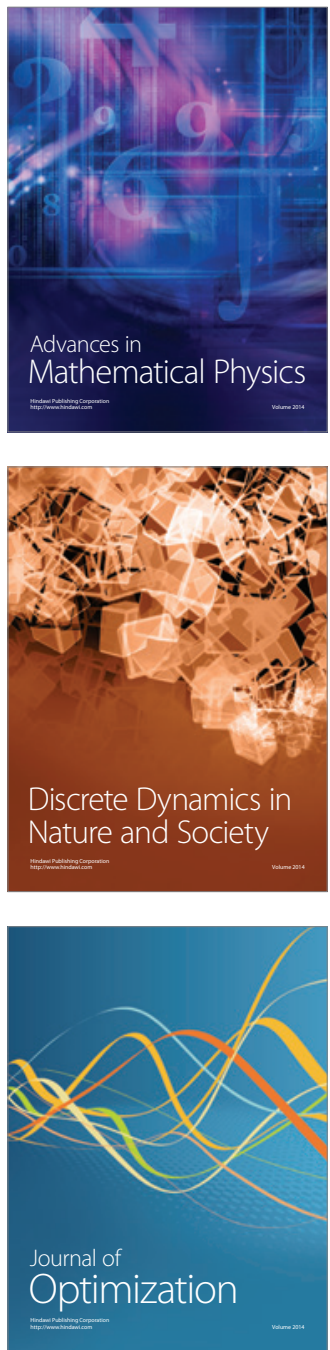